By this method no portion of the solution can enter the tissues at the point of injection.

It is important that distilled water should be used for making the solution. Tap water produces a fine suspension. We have had no untoward occurrences. There is always a rise of temperature followed by headache and vomiting, and in some cases rigors and diarrhoea.

The condition of the patient is a cause for anxiety at first, but within twenty-four hours all symptoms clear up. In men 0.4 gram, and in women 0.3 gram doses diluted in saline solution have been given.

The intramuscular method has the disadvantage that great pain follows the injection, which may persist for several days, and in some cases weeks. In two cases sterile abscesses occurred at the site of the injection. No culture could be obtained from them, neither could any arsenic be demonstrated. The reaction as regards pain, temperature, headache, vomiting, etc., seems to be much less in women than in men.

In conclusion, I owe mach to my house-surgeon, Dr. W. Messer, for his help in assisting me and making notes on the cases. I have also to thank Dr. Stopford Taylor and Dr. R. W. Mackenna for supplying me with some tubes of galvarsan before it was obtainable in this country; also Dr. Moore Alexander for isolating the spirocheete in doubtfal cases.

\section{THE CURATIVE EFFECT OF SALVARSAN IN FRAMBOESIA.}

BY HENRY ALSTON, M.B., GOVERNMENT MEDICAL OFFICER, TRINIDAD.

I STATED in my first communication in the BrITISH Medical Journal of February 18th, 1911, page 360, that the injection of 18 cases of yaws with salvarsan at the St. Augustine Yaws Hospital, Trinidad, on January 4th and 11 th, was followed by immediate and wonderfal improvement. I subsequently injected 3 cases, and I am now (February 18th) able to give the results in these 21 cases. Each received only one injection.

$$
\begin{array}{lllr}
\text { Cured } \quad \ldots & \ldots & \ldots & 13, \text { or } 61.9 \text { per cent. } \\
\text { Nearly cured } & \ldots & \ldots & 3 \text {, or } 14.3 \text { per cent. }
\end{array}
$$$$
\text { Stationary } \quad \ldots . \quad \ldots .5 \text {, or } 23.8 \text { per cent. }
$$

The shortest period taken to cure was thirteen days, and the longest twenty-eight days.

I find that salvarsan has no effect on yaws tubercles of the nostrils (tubercles situated at the junction of the mucous membrane of the nose and the skin). This failure was noticed in two cases treated by salvarsan and in one treated by serum.

The cases of yaws injected with serum taken from recovering salvarsan cases on the fourth or fifth day all improved for two or three weeks. Some remain stationary, and others have got worse. I believe that if yaws cases were injected with serum every seven or ten days they would be cured with three or four injections.

I injected a goat that had two kids a month old, with

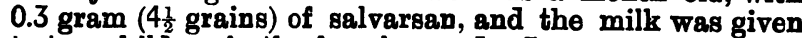
to two children in the female ward. Improvement begen in the children on the third day, and continued slowly and surely for fourteen days. The goat was borrowed for two weeks, and was sent back to the owner. I intend injecting a cow, and using the milk on a more extensive scale. If my experiment with a goat is verified by others (using more salvarsan than $I$ did) it means a complete overthrow of the theory of Professor Ehrlich, for it must be the salvarsan itself which produces the antibody, and it is probably of the nature of a ferment.

My further experiments with serum are not connected with salvarsan. I put blisters on some yaws cases and used the serum-dose $16 \mathrm{c.cm}$. for adults- to inject, each c8se getting his own serum. The object of this experiment was to see if the blistered surface secreted a beneficial substance. I got no results.

I put blisters on some cases cured of yaws by ordinary means, and used the serum on four yaws cases. There was a slight improvement, which did not last for more than a week.

I tried cacodylate of soda, arsacetin, orsudan, atoxyl, and soamin. I find that only orsudan and soamin are of some benefit in yaws. A 9-grain injection (adult dose) was given once a week. The formula given for soamin is the same as for atoxyl, and I am at a loss to account for the failure of atoxyl, a failure previously recorded by Professor Castellani in Ceylon.

I had salolized capsules prepared by the dispenser and filled with 1 grain of methylene blue and an inert sub. stance. The capsales were gummed and powdered with salol, and allowed to dry. This was done three times. When given to patients and healthy persons, four hours elapsed before the urine was discoloured, so I conclude that absorption takes place in the bowels. I am now trying sosmin in these personally tested capsules, and so far as the experiment has gone, it acts well. I will try salvarsan in this way, when a supply comes from England. I suggest the use of tested salolized capsules made with a double end, the small compartment containing 1 grain of methylene blue. On filling such a capsule with a drug, the discoloration of the urine would exactly indicate when absorption began.

It is my intention to try 1 per cent. injections of the hydrochloride of quinine and urea before injecting with salvarsan intramuscularly so as to mitigate the pain by producing local anaesthesia.

\section{SUMmaRY.}

Salvarsan is the best drug for use in yaws. I have no doubt that this fact has been discovered in every yaws hospital. The experiments in Trinidad have contributed to knowledge in four directions:

1. The serum of cases recovering under salvarsan' has been shown to have a curative effect.

2. Nostril yaws tubercles are not affected by salvarsan nor by serum.

3. The milk of a goat injected with salvarsan has a curative effect.

4. Soamin and orsudan are the only organic compounds -excluding salvarsan, of course-that cause some benefit in yows.

Full details of all my experiments are recorded and communicated to the Acting Surgeon.General of the Colony. My thanks are due to him and others for their appreciation and encouragement. Further experiments will be undertaken.

\section{The Science Commitee} 第xitits

\section{OBSERVATIONS ON THE OCCURRENCE OF FLUID IN THE ABDOMINAL CAVITY IN PREgNANT RABBITS.}

CHARLES BOLTON, and

D.Sc., M.D., F.R.C.P.

DIRECTOR OF RESEARCH DEPARTMENT, UNIVERSITY COLLEGE

\author{
A. M. H. GRAY, \\ M.D.LOND., F.R.C.S. \\ PHYSICIAN IN CHARGE, SKIN \\ DEPARTMENT, UNIVERSITY \\ COLLEGE HOSPITAL.
}

The presence of free fluid in the abdominal cavity of the pregnant rabbit has been noticed in the course of research by several observers, but as far as we are aware no special observations have been made with regard to the nature of the fluid present nor to the possible cause of its occurrence. It has occurred to us that some such observations may be of value, especially in relation to the work done by one of us (C. B.) on the pathology of cardiac dropsy.

Relative Frequency.-The relative frequency of free fluid in the peritoneal cavity has been estimated in a series of pregnant and mon-pregnant animals:

(a) Non-pregnant: Ten non-pregnant animals were examined, 4 males and 6 females, and although the intestines were moist in all cases, in only 2 was a measurable quantity of free fluid obtained, and in these 2 cases (1 male and 1 female) the quantity was very small, as indicated below.

(b) Pregnant: In 16 pregnant animals examined, we only failed in 2 cases to obtain a measurable quantity of fluid. This gives the following percentages of cases with free fluid:

(a) Non-pregnant, 20 per cent. (probably is much smaller).

(b) Pregnant, 87.5 per cent. 